\title{
Spatialities and temporalities of metrics calculated by Integrated Assessment Models: Exceedance of ecosystem-specific Critical Loads
}

\author{
$\underline{\text { T. Oxley }}^{\text {a }}$, J. Hall ${ }^{\mathrm{b}}$ and H. ApSimon ${ }^{\mathrm{a}}$ \\ ${ }^{a}$ Centre for Environmental Policy, Imperial College London, SW7 2AX, UK \\ ${ }^{b}$ Centre for Ecology \& Hydrology, Bangor, Gwynedd, LL57 2UW, UK \\ Email: t.oxley@imperial.ac.uk
}

\begin{abstract}
Integrated Assessment Models are designed to calculate a variety of metrics which describe the impacts upon ecosystems and human health resulting from specified spatial patterns of emissions of air pollutants. These metrics can provide policy makers with useful information which can assist in sustainable policy development and negotiation of international protocols. However, they can also present a very different picture of impacts depending upon the spatial resolution of the models used to describe emissions, atmospheric dispersion, deposition and air quality, and the metrics themselves may change as scientific understanding evolves over time. Using exceedance of ecosystem Critical Loads as an example of such metrics, we show how the area of critical load exceedances increases both as the spatial resolution of modelled deposition increases and as scientific advances in the representation of ecosystem specific deposition patterns are included in the models. Furthermore, advances in scientific understanding of Critical Loads, atmospheric dispersion and deposition rates can lead to apparently paradoxical quantifications of impacts when the effectiveness of policies are subsequently reviewed. Policy makers demand use of the most up-to-date science and may thus, when comparing against earlier assessments, discover an apparent increase in the ecosystem area exceeded due to scientific improvements in the models rather than reduced emissions; such results reflect the different and potentially conflicting temporalities of scientific developments and the policy making processes, as opposed to impacts in the real world. Thus, we also highlight the importance of coordinating these temporalities and using equivalent tools or models for both assessment of potential impacts of policies and any subsequent review of the effectiveness of those policies.
\end{abstract}

Keywords: Spatial and temporal resolution; critical loads; integrated assessment; Gothenburg Protocol 


\section{INTRODUCTION}

Integrated Assessment Models are designed to calculate metrics which describe the impacts upon ecosystems and human health resulting from specified spatial patterns of emissions of air pollutants. Such metrics can provide policy makers with useful information which can assist in sustainable policy development and negotiation of international protocols. The successes of integrated assessment modelling in relation to development of the Gothenburg Protocol [UNECE, 1999], the EU National Emissions Ceilings [EC, 2001] and urban air quality has been documented by Hordijk \& Amann (2007), continuing with the ongoing revision of the protocol [UNECE, 2010].

However, these metrics can also present a very different picture of impacts depending upon the spatial resolution of the models used to describe emissions, atmospheric dispersion, deposition and air quality, and calculation of the metrics themselves will change as scientific understanding evolves over time. Figure 1 presents an overview of the scientific and policy developments from the formation of EMEP [UNECE, 1984] to the ongoing revision of the Gothenburg Protocol, highlighting the 'new' science which was not available during negotiation of the original protocol. In summary, atmospheric dispersion modelling has evolved at the European scale from a $150 \mathrm{~km}^{2}$ resolution Lagrangian model calculating grid-average depositions to a $50 \mathrm{~km}^{2}$ Eulerian model which calculates ecosystem-specific deposition [Simpson et al., 2003]. Models have also been developed at $5 \mathrm{~km}^{2} / 1 \mathrm{~km}^{2}$ resolution (eg. FRAME [Fournier et al., 2005; Dore et al., 2009] and EMEP4UK [Vieno et al., 2009]) which are used by national integrated assessment models such as the UKIAM [Oxley et al., 2003; Oxley \& ApSimon, 2007].

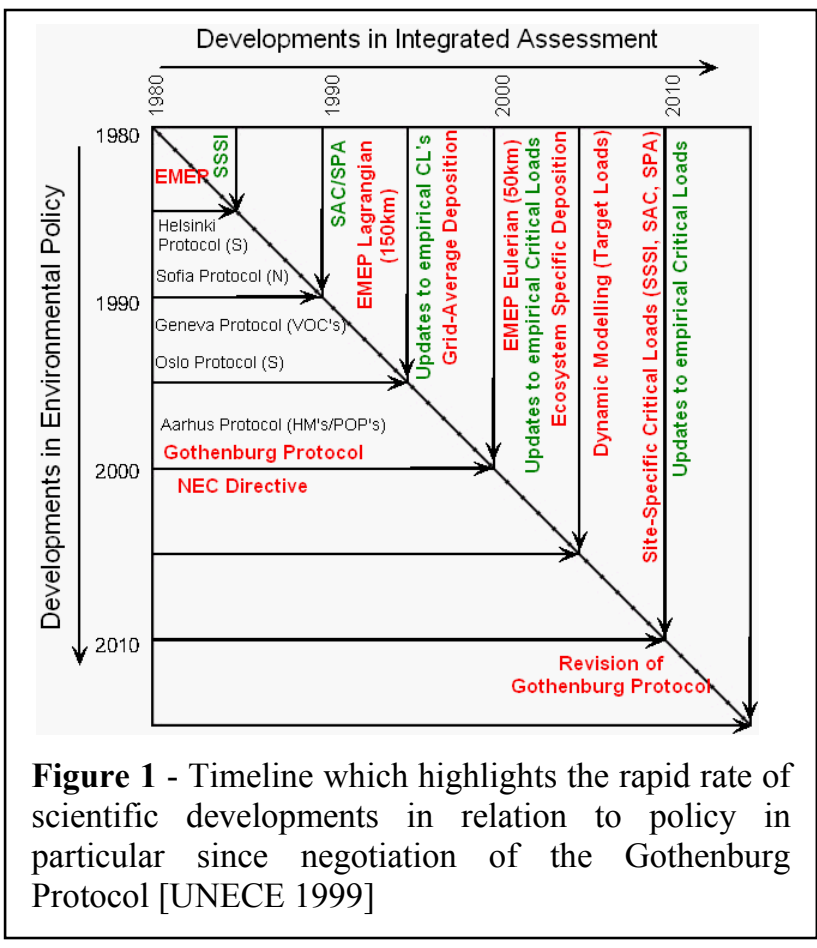

Furthermore, developments in Critical Loads (CL)

over the last two decades have progressed from the original acidity CL's for soils to include water and then ecosystems. These developments include changes to the chemical criteria and the development of and updates to empirical CL's for nutrient Nitrogen (CLnutN). These developments, based upon the best scientific evidence/knowledge, have been regularly reported in CCE Status Reports ${ }^{[1]}$; it is important to note that such updates can result in a decrease in the CL values (eg for empirical CLnutN for selected habitats), which implies an increase in exceedance for the affected ecosystems for no change in deposition rates. In addition to these developments to CL's, since negotiation of the Gothenburg Protocol dynamic modelling has been used to develop Target Loads [Hettelingh et al., 2007; Posch et al., 2003] which address recovery of ecosystems, whereas CL's only capture damage to ecosystems. Finally, whereas protocol negotiation focussed upon impacts on ecosystems and habitats nationally, subsequent application of Critical Loads to designated sites provides the ability to directly address impacts on SSSIs, SACs, SPAs and other Natura 2000 sites. [Hall et al., 2003; 2008; http://jncc.defra.gov.uk/].

The effect of these developments is that revision of the Gothenburg Protocol can benefit from greater scientific understanding of ecosystem impacts than was available during the original negotiation, which is undoubtedly a positive development. However, great care is needed when reviewing the present state of policy metrics against the impacts predicted upon the basis of earlier science, to ensure that assessments are comparing like with like. In the following sections we highlight the impact spatial resolution can have upon quantifications of metrics and the difficulties that contrasting temporalities in science and policy can create in specifying a consistent basis for comparison.

\section{SPATIAL RESOLUTION}

Using exceedance ${ }^{[2]}$ of ecosystem Critical Loads as an example metric, we show how the area of critical load exceedance increases both as spatial resolution of deposition data increases and as scientific advances in the

\footnotetext{
${ }^{[1]}$ Status reports from the Coordination Centre for Effects available from http://www.rivm.nl/en/themasites/cce/

[2] 'exceedance' is the rate of deposition of acidity $(\mathrm{S} / \mathrm{N})$ or nutrient $\mathrm{N}$ over and above the Critical Load for an ecosystem
} 
representation of ecosystem specific deposition patterns are included in the models. As the EMEP Eulerian model was still under development at the time of the Gothenburg Protocol, the $150 \mathrm{~km}^{2}$ resolution Lagrangian model provided the basis for negotiations [EMEP, 1998]. The significance of this in relation to exceedance of Critical Loads is that subsequent calculations were based upon the $50 \mathrm{~km}^{2}$ resolution model [Simpson et $a l ., 2003]$; immediately the area
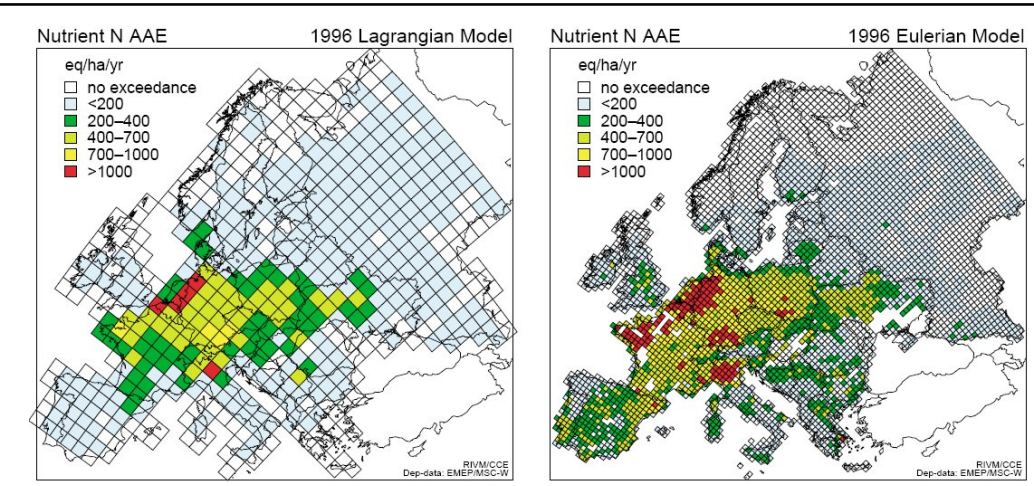

Figure 2 - A change in model resolution (from $150 \mathrm{~km}^{2}$ to $50 \mathrm{~km}^{2}$ ) significantly increases quantifications of exceedance and affects the spatial distribution of exceedance (from Posch et al., 2001) of exceedance increases, ceteris paribus, as shown in Figure 2.

Subsequent scientific developments in relation to the GAINS model and all constituent sub-models have been documented by Amann (2010), with an external review of the modelling methodology highlighting further implications, arising from the development of higher resolution national models, in relation to exceedance of critical loads [EC4MACS, 2009].

Estimates of risk for ecosystem damage have already been reported to be a factor of 3 higher for eutrophication (30-50\% for acidification) than estimates used during negotiation of the Gothenburg Protocol; this increase results from the shift to a higher resolution deposition model combined with updates to emissions and critical load data, the use of a chemical transport model for deposition, and land-cover specific deposition [Fagerli \& Tarrason, 2006]. This effect is further exacerbated when exceedances are calculated by the national scale UK Integrated Assessment Model at 5 $\mathrm{km}^{2}$ resolution [Oxley et al., 2003; Oxley \& ApSimon, 2007].

Figure 3 presents a comparison between the effects of using grid-average or ecosystem-specific deposition to calculate exceedance of eutrophication critical loads; when EMEP grid-average deposition is used, ceteris paribus, no exceedance is apparent except in a few hot-spots. Table 1 quantifies these variations in relation to area exceeded for the different deposition rates, with almost half the ecosystem area displaying exceedance when high resolution ecosystem-specific deposition is used as compared with less that $1 \%$ area exceeded when low resolution grid-average deposition is used. This difference has also been exacerbated by the inability of EMEP to adequately capture localised orographic enhancement and the spatial pattern of deposition with the
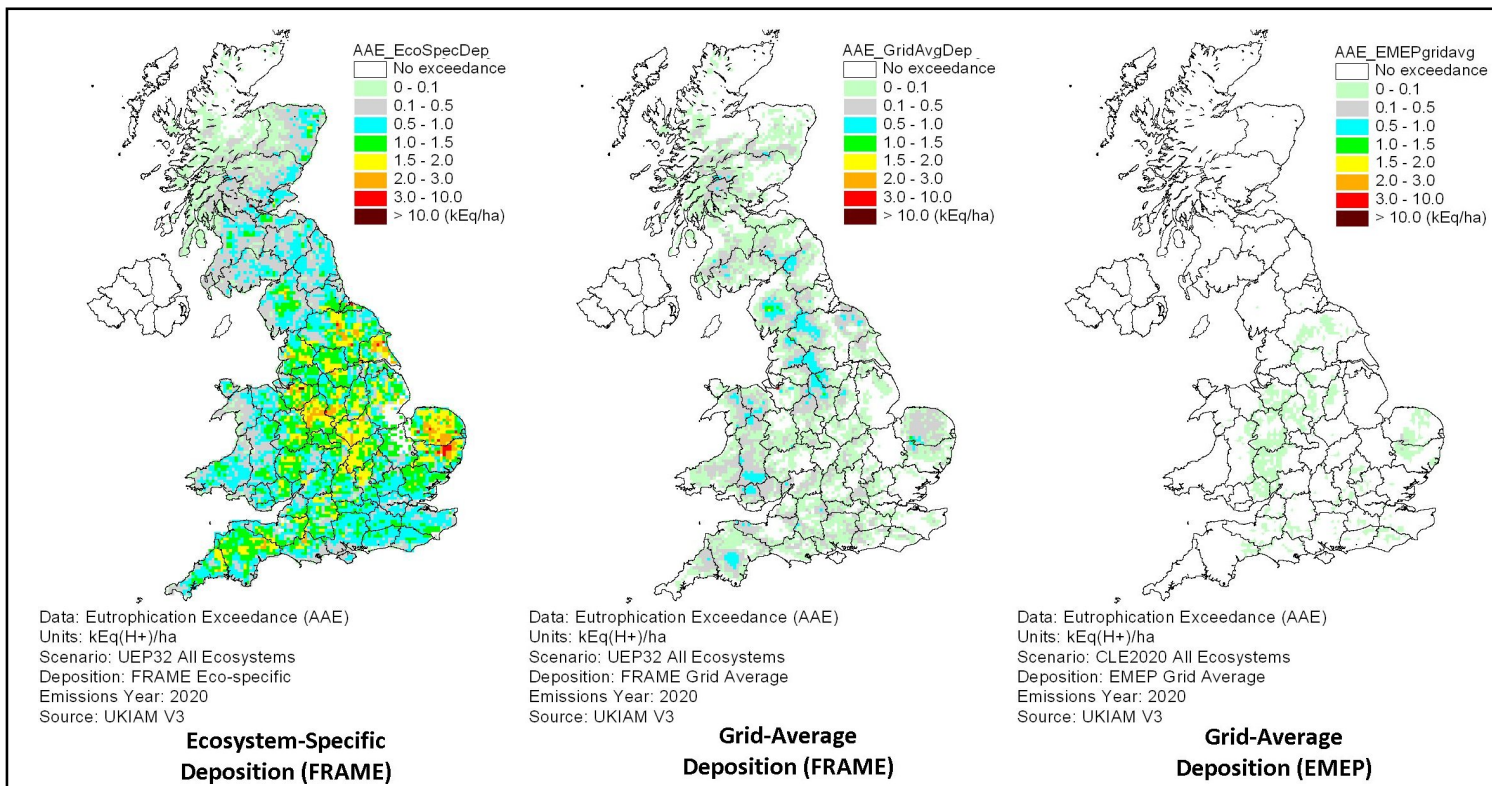

Figure 3 - Comparison of calculated average accumulated exceedance in 2020 of nutrient $\mathrm{N}$ critical loads in the UK (excluding N Ireland), for all ecosystems, based upon (a) FRAME ecosystem-specific deposition, (b) FRAME grid-average deposition, and (c) EMEP grid-average deposition 
highest deposition in the Southeast whereas FRAME shows greatest deposition in the Northwest.

Table 1 - Nutrient nitrogen exceedances (all habitats) for Great Britain based upon projected emissions in 2020, comparing effects of alternative deposition models. Sitespecific exceedances for SSSI's (see Figure 4) are also shown for comparison

\begin{tabular}{|l|r|r|r|}
\hline \multicolumn{1}{|c|}{ Source of deposition data } & $\begin{array}{c}\text { Exceeded Area } \\
\left(\mathrm{km}^{2}\right)\end{array}$ & $\begin{array}{c}\text { Percentage Area } \\
\text { Exceeded }\end{array}$ & $\begin{array}{c}\text { Accumulated } \\
\text { Exceedance } \\
\text { (kEq/year) }\end{array}$ \\
\hline FRAME - Ecosystem specific & 35,193 & 49.62 & $2,390,045$ \\
FRAME - Grid-average & 25,965 & 36.61 & 796,013 \\
EMEP - Grid-average & 684 & 0.96 & 4,119 \\
FRAME - Eco-specific (SSSI) & 13,375 & 64.61 & $1,175,693$ \\
\hline
\end{tabular}

It is clear from these examples that spatial resolution (of atmospheric dispersion modelling, specification of critical loads, etc.) is a significant factor in quantifying exceedances. Whereas the Gothenburg Protocol was negotiated based upon information such as shown in Figure 2 (with maximum exceedance of nutrient $\mathrm{N}$ critical loads in the UK less than $0.2 \mathrm{kEq} / \mathrm{ha}$ in 1996), current projections to 2020 suggest there may be exceedances greater than $10 \mathrm{kEq} / \mathrm{ha}$ in some areas even having taken into account the considerable emissions reductions between 1996 and 2020. Note that Figure 2 is based upon 1996 Critical Loads whereas Figure 3 is based upon the most recent updates, which will also affect the calculation of area exceeded,

This numerical effect is further exacerbated when exceedances are calculated using $1 \mathrm{~km}^{2}$ resolution deposition data or when analyses focus upon specific sites. Although quantification of exceedances (Figure 3) are useful for describing impacts nationally, this attaches equal importance to each ecosystem area, irrespective of whether it may be a Site of Special Scientific Interest (SSSI) or a European Natura 2000 site (which includes Special Areas of Conservation (SAC) designated under the EC Habitats Directive, and Special Protection Areas (SPA) protected by the EC Birds Directive). Thus, exceedances based upon site-specific critical loads have been developed [Hall et al., 2006; 2007], providing policy makers with information quantifying exceedances for different habitats and features for individual sites (see Figure 4); it should be remembered, however, that these data relate to only a subset of ecosystems nationally and therefore results cannot be directly compared with those for all habitats as described in Figure 3.

\section{TEMPORALITIES}

In addition to the spatial issues discussed above, advances in scientific understanding of critical loads, atmospheric dispersion and deposition rates can lead to apparently paradoxical quantifications of impacts when the effectiveness of policies are subsequently reviewed. The difference in exceedances displayed between Figure $2 \mathrm{a}$ and Figure $3 \mathrm{a}$ are not solely the effect of changing spatial resolution, but also influenced by more detailed critical load data [Hall et al., 2008], updates to dispersion models [Simpson et al., 2003; Dore et al., 2009, Fagerli \& Tarrason, 2006], and development of national scale integrated assessment models [Oxley et al., 2003; Oxley \& ApSimon, 2007].

In the context of reviewing the Gotheburg Protocol and quantifying the progress made towards protection of the environment relative to expectations, a choice is necessary between the extremes of using the latest emissions scenarios to drive the original $150 \mathrm{~km}$ Lagrangian model or using the Gothenburg emissions to drive the latest models. Both options have advantages and disadvantages, with a pragmatic compromise involving the most up-to-date models but using grid-

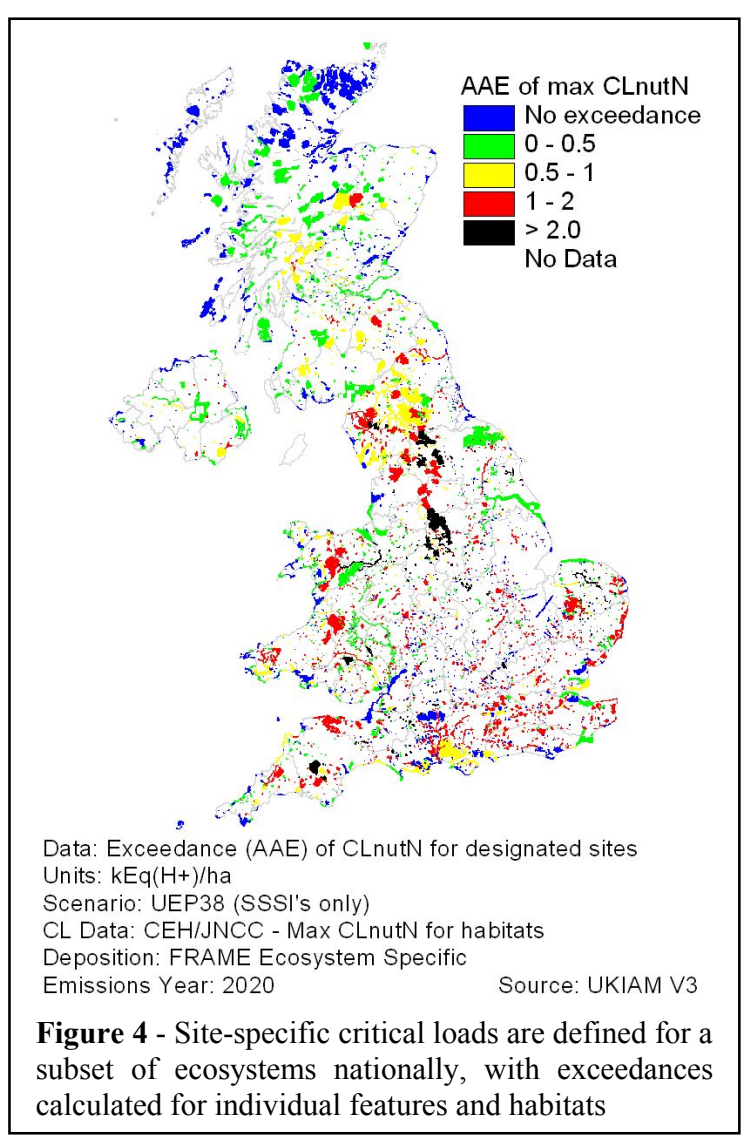


average deposition rates [TFIAM, 2007]; this overcomes the largest impact upon exceedance calculations (see Figures $3 \mathrm{a} / 3 \mathrm{~b}$ ), but will under-predict the impacts especially for woodland ecosystems where deposition rates are higher than average.

An additional conceptual issue for policy makers to grasp is what is the meaning of critical loads and what does non-exceedance imply? Critical Loads are, by definition, " $a$ quantitative estimate of exposure to one or more pollutants below which significant harmful effects on specified sensitive elements of the environment do not occur according to present knowledge" [Nilsson \& Grennfelt, 1988]. Any non-exceedance of critical loads therefore only implies that no additional damage is being done to these ecosystems. It does not imply that ecosystems have recovered or will recover from existing damage. To this end the concept of Target Loads was developed, based upon dynamic modelling, to describe " a deposition pathway which ensures recovery in a given year and maintained thereafter" [Hettelingh et al., 2007]. Unlike critical loads, unique target loads do not exist for a given ecosystem since target loads also capture the target year, the protocol year (when emissions reductions start) and the implementation year (emissions reductions complete), each of which are definable by policy makers.

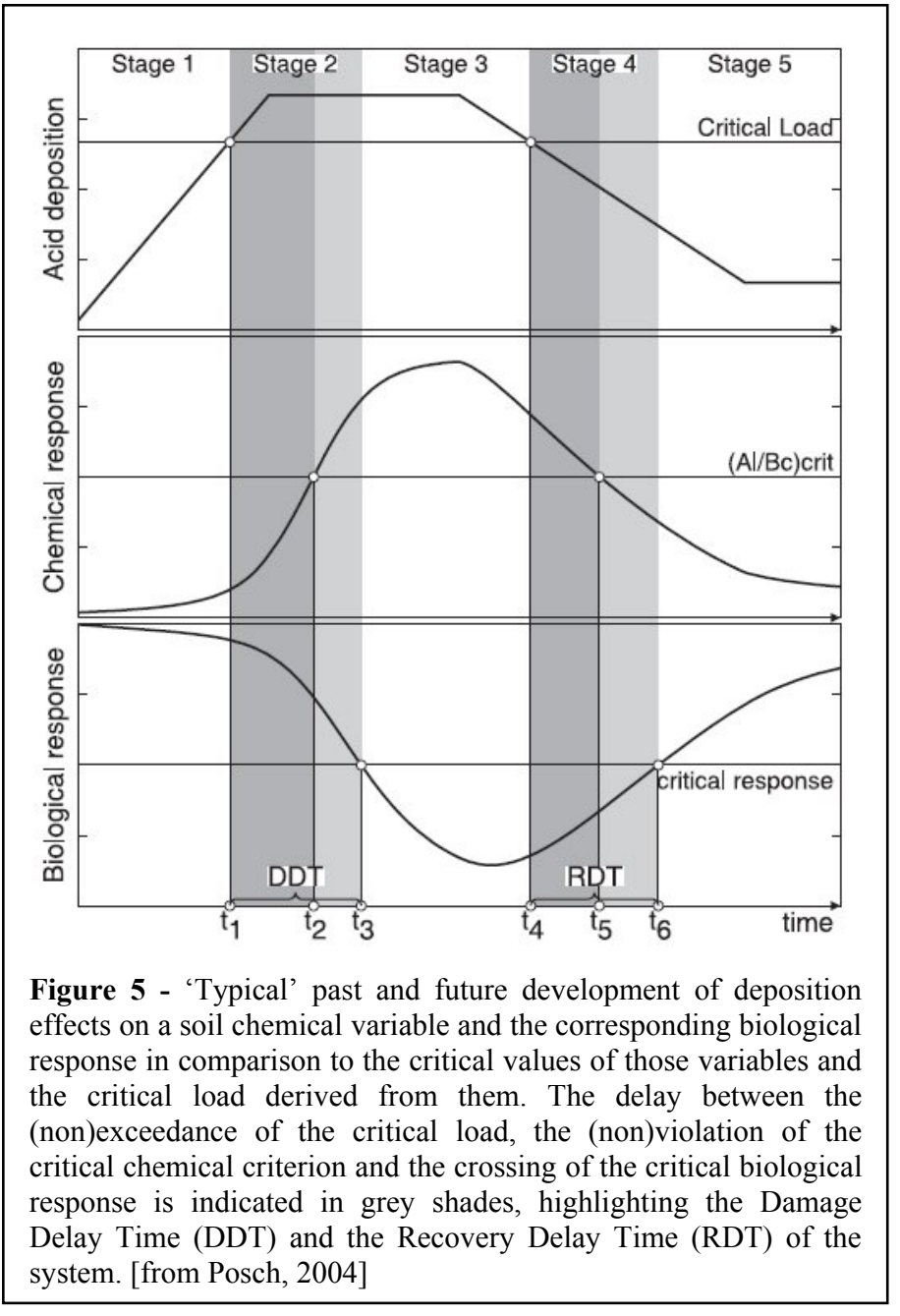
Target Loads aim to achieve a certain rate of deposition in a target year; a rate related to achieving a particular chemical status such as a specific soil $\mathrm{pH}$. However, achieving chemical recovery will not necessarily be accompanied by biological recovery, which could take much longer or not occur at all. This relationship between deposition, chemical response and biological response is shown in Figure 5, highlighting the potential delay times before recovery occurs. Clearly, more dramatic emissions reductions are required to meet target loads than to achieve non-exceedance of critical loads since recovery of damaged ecosystems is central to the concept of target loads [Jenkins et al., 2003].

The impact of these scientific developments upon policy making is to introduce a series of sometimes conflicting temporalities related to anthropogenic actions and environmental responses. The effect of interaction of such temporalities has been described elsewhere in the context of desertification in the Mediterranean, where farmers' daily irrigation needs can lead to aquifer depletion years or decades later, ultimately caused by shortterm financial decisions to replace olive production with oranges [Oxley et al., 2002]. Similar temporalities can be observed in relation to the protection of ecosystems under CLRTAP: emissions reductions now may promote ecosystem recovery in decades or even centuries, but this is further complicated by delays in negotiating and implementing emissions reductions. Subject to political feasibility of emissions reductions, it is clearly beneficial to aim for reductions to meet target loads, but since these are inherently dependent upon the timing of reductions, as delays in commencing action occur the extent of action required to achieve protection by a specified time will rapidly increase.

\section{DISCUSSION}

Policy makers demand use of the most up-to-date science and may thus discover an apparent increase in the ecosystem area exceeded when comparing against earlier assessments; such results may reflect changes to spatial resolution and/or the different and potentially conflicting temporalities of scientific developments and the policy making processes, as opposed to impacts in the real world. This highlights two key issues to be taken into account: 
Firstly, any review of impacts of previous/existing policies should ensure that there is an appropriate degree of comparability between the tools used for negotiation and those used for review. For practical and scientific reasons reverting to the original tools in their entirety often makes little sense, hence the use of the most recent data and models for review of the Gothenburg Protocol but utilising grid-average deposition rates since ecosystem-specific deposition rates were unavailable at the time of negotiation [TFIAM, 2007]. It is important to ensure that policy makers are provided with appropriate information (data, maps etc.) which enable them to compare like with like, with sufficient clarification to make the differences between results explicit.

Secondly, given the extent of recent scientific developments, different policy makers and stakeholders will be observing and interpreting impacts from different spatial perspectives (from the local to the international) and focussing upon alternative metrics describing the state of the environment. Whereas national or European policy perspectives may be satisfied with nationally aggregated representations of average accumulated exceedances for all habitats, scientists' perspectives may have moved forward to observe metrics which look beyond exceedance of critical loads to metrics based upon target loads and issues of biodiversity, ecosystem health, species richness etc. [Slootweg, 2010]. Resolving these different perspectives of effects should therefore be made explicit during review/negotiation in order to arrive at a coherent collective understanding of both the rate and extent of emissions reductions required to achieve new targets of environmental protection.

Understanding these inherent implications and temporalities is important to ensure that any misrepresentation of the expected effects of emissions abatement policies can be avoided. If a policy scenario suggests that exceedance of critical loads can be reduced and this is interpreted as protecting ecosystems (as opposed to doing no further damage) there is a likelihood that further emissions reductions will be required in the future to ensure recovery from damage already caused. It is probable that significant reductions of the current exceedance of critical loads will result from emissions reductions already planned [TFIAM, 2007]. However, in order to promote ecosystem recovery, which may take decades or more, significantly greater emissions reductions will be required which may be economically or politically prohibitive; as suggested by Figure 5, target loads are dynamic and delays in either the 'protocol year' or the 'implementation year' will make it increasingly difficult to achieve ecosystem recovery.

The dynamic nature of target loads and potentially long recovery timescales for ecosystems demand that action should be sooner rather than later. However, political temporalities and delays in policy development, negotiation and implementation of protocols will also affect the extent of action required. Furthermore, in the current economic climate, for example, can policy makers be expected to prioritise the possibly expensive recovery of ecosystems by next century when "it's the economy, stupid"? ${ }^{[3]}$ Such questions are beyond the scope of this paper but serve to highlight political perspectives influencing policy development which must also be considered when interpreting critical load exceedances and target loads.

\section{CONCLUSIONS}

In this paper we have described the spatial and temporal issues influencing modelled predictions of the effects of past and future emissions scenarios upon exceedance of Critical Loads, which are then used as the basis for policy developments towards protection of the natural environment. The publication of regular status reports ${ }^{[4]}$ ensures openness and transparency of the data and methods used to calculate Critical Loads so that, when updates are made, policy makers are provided with detailed information on the impact these changes may have on the calculation of critical load exceedances so they understand the cause of the change and that results are not misinterpreted.

Finally, we have shown that the differences in results presented to policy makers may be due to one or more of the following:

- $\quad$ Scientific developments in deposition modelling: Ranging from EMEP Lagrangian to Eulerian dispersion models, from grid-average to ecosystem-specific deposition, and from $150 \mathrm{~km}^{2}$ to $50 \mathrm{~km}^{2}$ resolution, and at the UK scale from $20 \mathrm{~km}^{2}$ resolution in the late 1980 's to $10 \mathrm{~km}^{2}, 5 \mathrm{~km}^{2}$ and $1 \mathrm{~km}^{2}$ resolution deposition [Dore et al., 2009; Smith et al., 2000]; Differences in spatial patterns of modelled deposition with EMEP showing highest deposition in the Southeast of the UK and FRAME showing highest deposition in the Northwest with orographic enhancement in mountainous areas;

- Improvements in the science and understanding of effects and the development of Critical Loads: In the UK this started with an acidity CL map for soils, one for UK freshwaters (selected sites only), followed by ecosystem-specific acidity CL's and the use of different chemical criteria; For nitrogen the empirical

\footnotetext{
${ }^{[3]}$ Quote used by John Carville, Bill Clinton's presidential campaign strategist (1992)

${ }^{[4]}$ See http://www.rivm.nl/en/themasites/cce/publications/ and http://cldm.defra.gov.uk/Status_Reports.htm
} 
Oxley et al., Spatialities \& temporalities of metrics in integrated assessment models

CLnutN have been periodically reviewed/updated internationally with increased knowledge of impacts resulting in decreases in CLnut $N$ for some habitats; or

- Changing emissions scenarios: Changes in the quantification and recording of emissions, the sources captured (including natural), and updates to future emissions projections.

\section{REFERENCES}

Amann, M. (ed.), 2010, Greenhouse gases and air pollutants in the European Union: Baseline projections up to 2030, EC4MACS Interim Assessment, http://www.ec4macs.eu/

Dore, A., Kryza, M., Hallsworth, S., Matejko, M., Vieno, M., Hall, J., van Oijen, M., Zhang, Y., Smith, R. \& Sutton, M., 2009, Modelling the deposition and concentration of long range air pollutants, Final Report to Defra, Contract CPEA34

EC, 2001. Directive 2001/81/EC of the European Parliament and of The Council of 23 October 2001 on national emissions ceilings for certain atmospheric pollutants.

EC4MACS, 2009, Workshop on the review of modelling methodology, IIASA, Laxenburg, Austria, 5 October 3009, http://www.ec4macs.eu/

EMEP, 1998, Transboundary acidifying air pollution in Europe, Part 1: Estimated dispersion of acidifying and eutrophying compounds and comparison with observations, MSC-W Status Report 1/98

Fagerli, H. \& Tarrason, L., 2006, Contribution from MSC-W to the review of the Gothenburg Protocol, Report to $32^{\text {nd }}$ meeting of UN/ECE Task Force on Integrated Assessment Modelling, Rome, 16-18 May 2006

Fournier, N., K.J. Weston, A.J. Dore and M.A. Sutton, 2005, Modelling the wet deposition of reduced nitrogen over the British Isles using a Lagrangian multi-layer atmospheric transport model. Quarterly Journal of the Royal Meteorological Society, 131, 703-722.

Hall, J. (ed.), 2003, Status of UK Critical Loads: Critical Loads Methods, Data and Maps. UK National Focal Centre, Centre for Ecology \& Hydrology, February 2003, http://critloads.ceh.ac.uk/

Hall, J., Bealey, W. \& Wadsworth, R. 2006. Assessing the risks of air pollution impacts to the condition of Areas/Sites of Special Scientific Interest in the UK. JNCC Report No. 387. JNCC Peterborough.

Hall, J., Ullyett, J., Wadsworth, R.A. \& Reynolds, B. 2007. The applicability of national critical loads data in assessing designated sites. Water, Air and Soil Pollution: Focus, 7: 413-419. DOI: 10.1007/s11267-006-9091-9

Hall, J., Evans, C., Rowe, E. \& Curtis, C., 2008, UK National Focal Centre report. In: Hettelingh, J.P., Posch, M., Slootweg, J. (eds.) Critical load, dynamic modelling and impact assessment in Europe: CCE Status Report 2008, Coordination Centre for Effects, Netherlands Environmental Assessment Agency, 211-216 (http://www.rivm.nl/cce)

Hettelingh, J., Posch, M., Slootweg, J., Reinds, G., Spranger, T. \& Tarrason, L., 2007, Critical Loads and Dynamic Modelling to Assess European Areas at Risk of Acidification and Eutrophication, 379-384, in [Brimblecombe et al. (eds.), 2007, Acid Rain - Deposition to Recovery, Springer Netherlands, ISBN: 978-1-4020-5885-1]

Hordijk, L. \& Amann, M., 2007. How science and policy combined to combat air pollution problems. Environmental Policy \& Law 37 (4), 336-340.

Jenkins, A., Cosby, B. J., Ferrier, R. C., Larssen, T. \& M. Posch, 2003, Assessing emission reduction targets with dynamic models: deriving target load functions for use in integrated assessment, Hydrological \& Earth System Sciences, 7(4), 609-617

Nilsson, J. \& Grennfelt, P. (eds.), 1988, Critical loads for sulphur and nitrogen - report from a workshop held at Skokloster, Sweden, March 19-24, 1988. The Nordic Council of Ministers. Report 1988:15, Copenhagen, Denmark.

Oxley, T. \& ApSimon, H.M., 2007, Space, time and nesting Integrated Assessment Models, Environmental Modelling \& Software, 22, 1732-1749

Oxley, T., ApSimon, H., Dore, A., Sutton, M., Hall, J., Heywood, E., Gonzales del Campo, T., \& Warren, R., 2003, The UK Integrated Assessment Model, UKIAM: A national scale approach to the analysis of strategies for abatement of atmospheric pollutants under the CLRTAP, Integrated Assessment, 4(4), 236-249

Oxley, T., Jeffrey, P. \& Lemon, M., 2002, Policy relevant modelling: relationships between water, land-use and farmer decision processes, Integrated Assessment, 3(1), 30-49

Posch, M. (ed.), 2004, Chapter VI: Dynamic Modelling, in [Mapping Manual 2004: Manual on methodologies and criteria for modelling and mapping critical loads \& levels and air pollution effects, risks and trends, ICP Modelling \& Mapping, UN/ECE Convention on Long Range Transboundary Air Pollution, www.icpmapping.org]

Posch, M., de Smet, P., Hettelingh, J-P. \& Downing, R. (eds.), 2001, Modelling and mapping of critical thresholds in Europe, CCE Status Report 2001, ISBN 96-9690-092-7

Posch, M., Hettelingh, J-P., Slootweg, J. \& Downing, R. (eds.), 2003, Modelling and mapping of critical thresholds in Europe, CCE Status Report 2003, ISBN 90-6960-106-0

Simpson, D., Fagerli, H., Jonson, J., Tsyro, S., Wind, P., Tuovinen, J., 2003. Unified EMEP model description, EMEP Status Report Part I. http://www.emep.int/UniDoc/

Slootweg, J., Posch, M. \& Hettelingh, J-P (eds.), 2010, Progress in the modelling of critical thresholds and dynamic modelling, including impacts on vegetation in Europe, CCE Status Report 2010, ISBN 978-90-6960-249-3

Smith, R.I., Fowler, D., Sutton, M.A., Flechard, C. \& Coyle, M., 2000, Regional estimation of pollutant gas deposition in the UK: model description, sensitivity analyses and outputs. Atmospheric Environment 34, 3757-3777

TFIAM, 2007, Review of the Gothenburg Protocol, Report of the Task Force on Integrated Assessment Modelling \& the Centre for Integrated Assessment Modelling, CIAM Report 1/2007, http://www.unece.org/env/lrtap/TaskForce/tfiam/

UNECE, The 1984 Geneva Protocol on Long-term Financing of the Cooperative Programme for Monitoring and Evaluation of the Long-range Transmission of Air Pollutants in Europe (EMEP), http://www.emep.int/

UNECE, The 1999 Gothenburg Protocol to abate acidification, eutrophication and ground-level ozone, United Nations/Economic Cooperation in Europe. http://www.unece.org/env/lrtap/. 
Oxley et al., Spatialities \& temporalities of metrics in integrated assessment models

UNECE, 2010, EMEP Steering Board, Workshop on Strategies \& Review, Report by the Chair of the Task Force on Integrated Assessment Modelling, ECE/EB.AIR/GE.1/2010/4, 34 ${ }^{\text {th }}$ Session, Geneva, 30 August -3 September 2010

Vieno, M., Dore, A., Wind, P., Di Marco, C., Nemitz, E., Phillips, G., Tarrasón, L. \& M. Sutton, 2009, Application of the EMEP Unified Model to the UK with a horizontal resolution of $5 \times 5 \mathrm{~km}^{2}, 367-372$, in [Sutton et al. (eds.), 2009, Atmospheric Ammonia, Springer Netherlands, ISBN 978-1-4020-9121-6] 